\title{
Cardiac magnetic resonance myocardial feature- tracking: the effect of treatment in patients with adult-onset growth hormone deficiency and acromegaly
}

Mahvesh R Javaid ${ }^{1 *}$, lan S Stone ${ }^{1}$, Ashley B Grossman ${ }^{2}$, Marta Korbonits $^{3}$, Julia D Thomas ${ }^{3}$, Steffen E Petersen ${ }^{1}$, Ceri Davies ${ }^{1}$

From 16th Annual SCMR Scientific Sessions

San Francisco, CA, USA. 31 January - 3 February 2013

\section{Background}

We have previously documented abnormalities in cardiac structure in patients with adult-onset growth hormone deficiency (GHD) and acromegaly which partially resolved during treatment (Dattani et al. 2012, Zemrak et al. 2012).

No treatment effect was seen on global measures of cardiac function e.g. left ventricular ejection fraction.

The aim of this study was to use quantitative strain parameters from cardiac magnetic resonance (CMR) myocardial feature tracking (FT) to assess regional changes in function before and after treatment in patients with GHD and acromegaly.

\section{Methods}

10 patients with GHD, 13 patients with acromegaly and 23 age- and sex-matched normal controls underwent CMR. Patients underwent scanning before and again 12 months after treatment. Radial and circumferential strain parameters were derived from 2-chamber $(2 \mathrm{CH})$, 4-chamber
$(4 \mathrm{CH})$ and basal, mid and apical short axis cine-images using dedicated FT software (Diogenes MRI, TomTec Imaging Systems, Munich, Germany). Comparisons between groups were performed using the $\mathrm{T}$-test.

\section{Results}

There were no significant differences in any FT derived parameters between normal controls and patients with GHD.

There was a significant difference in $4 \mathrm{CH}$-circumferential strain in patients with acromegaly compared to normal controls $(-7.6 \%$ vs $-5.0 \%, p=0.01)$. There were no significant differences in the remaining parameters.

The effect of treatment on FT derived indices is shown in Tables 1 and 2.

\section{Conclusions}

Other than 4-CH circumferential strain, no differences were seen in any FT derived strain measurements between

Table 1 The effect on feature-tracking parameters before and after one year of treatment in acromegaly patients.

\begin{tabular}{|c|c|c|c|c|c|c|c|c|c|c|}
\hline $\begin{array}{l}\text { Feature-tracking } \\
\text { Parameters }\end{array}$ & 2C Pre & 2C Post & 4C Pre & 4C Post & Basal Pre & Basal Post & Mid Pre & Mid Post & Apex Pre & Apex Post \\
\hline Radial Strain (\%) & $16.6 \pm 6.9$ & $14.9 \pm 5.2$ & $13.1 \pm 6.3$ & $15.1 \pm 3.9$ & $22.2 \pm 14.4$ & $20.0 \pm 5.7$ & $18.7 \pm 7.7$ & $16.1 \pm 6.0$ & $17.1 \pm 5.8$ & $19.5 \pm 15.9$ \\
\hline $\begin{array}{l}\text { Circumferential } \\
\text { Strain (\%) }\end{array}$ & $-7.17 \pm 2.8$ & $-7.23 \pm 2.4$ & $-7.55 \pm 1.9$ & $-5.69 \pm 2.0$ & $-9.87 \pm 2.3$ & $-10.4 \pm 1.6$ & $-9.19 \pm 3.0$ & $-8.86 \pm 2.3$ & $-9.99 \pm 2.7$ & $-10.6 \pm 3.4$ \\
\hline
\end{tabular}

${ }^{1}$ Cardiovascular Biomedical Research Unit, Barts and the London School of

Medicine and Dentistry, Queen Mary, University of London, London, UK

Full list of author information is available at the end of the article

(c) 2013 Javaid et al; licensee BioMed Central Ltd. This is an Open Access article distributed under the terms of the Creative Commons 
Table 2 The effect on feature-tracking parameters before and after one year of treatment in GHD patients.

\begin{tabular}{lcccccccccc}
\hline $\begin{array}{l}\text { Feature-tracking } \\
\text { Parameters }\end{array}$ & 2C Pre & 2C Post & 4C Pre & 4C Post & Basal Pre & Basal Post & Mid Pre & Mid Post & Apex Pre & Apex Post \\
\hline Radial Strain (\%) & $16.3 \pm 5.8$ & $19.4 \pm 5.2$ & $14.8 \pm 5.2$ & $14.0 \pm 6.5$ & $20.5 \pm 8.1$ & $19.4 \pm 7.5$ & $17.0 \pm 5.4$ & $15.1 \pm 2.2$ & $19.0 \pm 9.0$ & $16.1 \pm 8.6$ \\
\hline $\begin{array}{c}\text { Circumferential } \\
\text { Strain (\%) }\end{array}$ & $-7.83 \pm 1.7$ & $-7.59 \pm 2.05$ & $-6.07 \pm 3.4$ & $-4.72 \pm 5.3$ & $-10.7 \pm 2.6$ & $-10.2 \pm 2.6$ & $-8.43 \pm 4.2$ & $-9.25 \pm 2.5$ & $-9.62 \pm 2.7$ & $-8.84 \pm 3.3$ \\
\hline
\end{tabular}

The values represent mean \pm 1SD Abbreviation: $2 C-2$ Chambers, $4 C-4$ Chambers, Pre - Pretreatment, Post - Post-treatment

patients with GHD and normal controls, patients with acromegaly and normal controls and following 12 months of treatment.

The structural changes seen in patients with acromegaly and GHD deficiency may, therefore, precede significant functional abnormalities. Early identification and treatment of these patients may prevent the development of functionally important myocardial damage.

\section{Funding}

This study has been supported by departmental grants from NIHR, Pfizer and Novartis.

\section{Author details}

${ }^{1}$ Cardiovascular Biomedical Research Unit, Barts and the London School of Medicine and Dentistry, Queen Mary, University of London, London, UK. ${ }^{2}$ Oxford Centre for Diabetes, Endocrinology and Metabolism, University of Oxford, Oxford, UK. ${ }^{3}$ Centre for Endocrinology, William Harvey Research Institute, Barts and the London School of Medicine and Dentistry, Queen Mary, University of London, London, UK.

Published: 30 January 2013
Cite this article as: Javaid et al: Cardiac magnetic resonance myocardial feature-tracking: the effect of treatment in patients with adult-onset growth hormone deficiency and acromegaly. Journal of Cardiovascular Magnetic Resonance 2013 15(Suppl 1):E55.
Submit your next manuscript to BioMed Central and take full advantage of:

- Convenient online submission

- Thorough peer review

- No space constraints or color figure charges

- Immediate publication on acceptance

- Inclusion in PubMed, CAS, Scopus and Google Scholar

- Research which is freely available for redistribution

Submit your manuscript at www.biomedcentral.com/submit
C Biomed Central 